\title{
The relationship between fear of COVID-19 and mental health problems:
} A meta-analysis

Zeynep Şimşir ${ }^{a}$, Hayri Koç ${ }^{a}$, Tolga Seki ${ }^{a}$, and Mark D. Griffiths ${ }^{b}$

aDepartment of Guidance and Psychological Counseling, Necmettin Erbakan University, Konya, Turkey; ${ }^{\text {bS }}$ chool of Social Sciences, Nottingham Trent University, Nottingham, United Kingdom

\section{ABSTRACT}

The coronavirus disease-2019 (COVID-19) pandemic has caused physical and mental health problems among individuals around the world. Recent studies have reported various mental health problems among both health-care workers and the general population. In this metaanalysis, evidence is provided concerning the relationships between the Fear of COVID-19 Scale. The fear of COVID-19 scale: Development and initial validation. International Journal of Mental Health and Addiction] - the most widely used, translated, and validated scale and mental health problems including, anxiety, stress, depression, distress, post-traumatic stress, and sleep problems among the general population. We searched for relevant studies on Web of Science, Google Scholar, PubMed, and ERIC databases and conducted a metaanalysis with selected studies in accordance with the inclusion criteria. A total of 33 studies met the inclusion criteria. The results demonstrated that fear of COVID-19 was strongly related to anxiety $(r=0.55, n=19,578)$, traumatic stress $(r=0.54, n=8,752)$, distress $(r=0.53, n=11,785)$ as well as being moderately related to stress $(r=0.47, n=4,340)$ and depression $(r=0.38, n=23,835)$. The correlation with insomnia $(r=0.27, n=2,114)$ was modest. These results demonstrate that fear of COVID-19 is associated a wide range of mental health problems among the general population.

\section{Introduction}

The coronavirus disease-2019 (COVID-19) first emerged in Wuhan, China in November 2019, and then rapidly spread all over the world causing major public health challenges. At the time of writing (February 2021), 223 countries, domains, or territories had experienced COVID-19 outbreaks around the world (World Health Organization [WHO], 2020a). Also, according to the World Health Organization (WHO, 2020b), the number of individuals worldwide that have been infected is over 102.1 million and the number of deaths is over 2.2 million since the first case was officially identified. Given the global spread of virus, all governments have taken measures and imposed restrictions to slow down and control the spread of the disease. These restrictions have included closure of all educational establishments and non-essential businesses, travel restrictions, and quarantine measures, as well as spatial distancing and the compulsory wearing of 
face masks in public places. For instance, many countries introduced nationwide lockdowns and limited citizens traveling to other cities and/or countries (BBC News, 2020; Ministry of the Interior, 2020). Consequently, all these restrictions have adversely affected individuals' mental and/or physical health (Lee \& Neimeyer, 2020; RodríguezHidalgo et al., 2020; Smith et al., 2020).

Since the COVID-19 pandemic became an increasingly uncontrollable stressor and mental health concern, an increasing number of empirical studies have been carried out in many different countries. Additionally, the mass media have given attention to an increase in mental health challenges (Lakhan et al., 2020). Professionals have also addressed common mental health responses of individuals concerning their worries about the growing number of mental health issues (Xiang et al., 2020).

Fear is among the most prevalent psychological responses to pandemic diseases and is different from other disasters (Ahorsu, Lin, Imani et al., 2020). Normally, fear is an adaptive reaction to a real or abstract threat that ensures survival (Gullone, 2000). Scholars (e.g., Harper et al., 2020; Li et al., 2020) have emphasized that fear could have a functional role in encouraging a series of behaviors that decrease engagement in risky actions and promote safety actions such as spatial distancing and hand hygiene during the pandemic period. However, numerous adverse conditions such as social isolation, uncertainty, having a chronic illness, financial problems, interruption of daily routines, losing family members because of COVID-19, and being in a risky age group (60+ years) have increased the level of fear during the COVID-19 pandemic (e.g., Bitan et al., 2020; Coelho et al., 2020; Satici et al., 2020; Smith et al., 2020). Indeed, a high level of fear can become harmful and negatively affect activation in various regions of the brain (Shin \& 
Liberzon, 2010). Therefore, extreme fear may prevent individuals from responding to the COVID-19 pandemic in a rational manner (Ahorsu, Lin, Imani et al., 2020).

As with previous pandemics, the perception of personally threatening situations has created extreme fear among some individuals during the COVID-19 pandemic (Rodríguez-Hidalgo, 2020). Such fear has severely disrupted the mental health of millions of individuals worldwide (Mahmud et al., 2020). To assess this new fear, Ahorsu, Lin, Imani et al. (2020) developed the Fear of COVID-19 Scale (FCV-19S) to be utilized in studies to better understand fear of COVID-19's association with various mental health outcomes related to COVID-19 and to help evaluate COVID-19 preventive behaviors among diverse populations. Although various instruments have been developed in the literature to assess fear-related aspects of COVID-19 (e.g., instruments assessing anxiety towards COVID-19), the present study only included the studies utilizing the FCV-19S because this is the most used scale and has been translated and validated in over 15 languages and has demonstrated very good psychometric properties (Pakpour et al., 2020; Ransing et al., 2020) and is the only widely used scale that has specifically assessed fear of COVID-19. For example, FCV-19S has been translated and utilized in many countries including Argentina (Caycho-Rodríguez et al., 2020), Bangladesh (Sakib et al., 2020), Brazil (Cavalheiro et al., 2020), Columbia (Cassiani-Miranda et al., 2021), Cuba (Broche-Pérez et al., 2020), Ethiopa (Elemo et al., 2020), Greece (Tsipropoulou et al., 2020), India (Doshi et al., 2020), Israel (Bitan et al., 2020), Italy (Soraci et al., 2020), Japan (Wakashima et al., 2020), Malaysia (Pang et al., 2020), Mexico (García-Reyna et al. 2020), New Zealand (Winter et al., 2020), Norway (Iversen et al., 2021), Pakistan (Mahmood et al., 2020), Peru (Huarcaya-Victoria et al., 2020), Portugal (Magano et al., 
2021), Russia (Reznik et al., 2020), Saudi Arabia (Alyami et al., 2020), Spain (MartínezLorca, et al., 2020), Turkey (Satici et al., 2020), United Kingdom (Harper et al., 2020), and the United States (Perz et al., 2020). Therefore, in this meta-analysis, we focused solely on studies that have used the FCV-19S to assess fear of COVID-19.

Additionally, numerous empirical studies have addressed the adverse outcomes associated with fear of COVID-19. This research has found that fear of COVID-19 is associated with many psychological and mental health issues including anxiety (Harper et al., 2020), stress (Rodríguez-Hidalgo et al., 2020), depression (Voitsidis et al., 2020; Mahmud et al., 2020), psychological distress (Saravanan et al., 2020), sleep problems (Linet al., 2020), post-traumatic stress (Kira et al, 2020), and obsession (Srivastava et al., 2020). Furthermore, some of these mental health issues (such as depression) can be major contributory factors underlying suicidal behaviors (Mamun \& Griffiths, 2020). To date, numerous cases of COVID-19-related suicides have been reported in various countries across the world including Bangladesh, India, and the United Kingdom (Mamun \& Griffiths, 2020; Miller, 2020). Therefore, Mamun and Griffiths (2020) recommended that levels of fear, anxiety, helplessness in relation to mental health issues was needed to help prevent such cases occurring in the first place and to help develop well-being strategies.

To provide a more comprehensive overview of the role of fear of COVID-19 in various mental health issues, the present study investigated the relationships between fear of COVID-19 and mental health problems utilizing meta-analysis. To the best of the authors' knowledge, no previous study has used meta-analysis to systematically examine these relationships among the general population. Furthermore, it is not known which mental health problems appear to be triggered more by fear of COVID-19 among the 
general public. Therefore, the meta-analysis presented here provides a comprehensive overview of studies performed to date on fear of COVID-19 using the FCV-19S and its association with mental health problems in the extant literature. Summarizing existing studies would help mental health professionals develop preventive and treatment approaches for such individuals. More specifically, the present study examined the extent to which fear of COVID-19 as measured by the FCV-19S is associated with different forms of mental health problems including anxiety, distress, stress, traumatic stress, depression, and insomnia.

\section{Method}

\section{Literature search and inclusion criteria}

The present meta-analysis focused on the fear of COVID-19 and mental health problems (i.e., depression, anxiety, stress, distress, traumatic stress, and insomnia). Searches were conducted for relevant studies using the Web of Science, Google Scholar, PubMed, and ERIC databases. We also performed a journal-specific search within the International Journal of Mental Health and Addiction, Frontiers in Psychology, Journal of Loss and Trauma, and Death Studies. Searches for studies were carried in databases using the following search string: ("fear*") AND ("COVID" OR "COVID-19" OR "coronavirus" OR "SARS-CoV-2" OR "SARScoronavirus"). The searches included published journal papers. We examined all papers for using the following inclusion criteria: (i) correlational studies examining the Fear of COVID-19 Scale (Ahorusu, Lin, Imani et al., 2020) and mental health problems, including depression, anxiety, stress, distress, traumatic stress, and insomnia; (ii) studies with large enough sample sizes to 
calculate effect sizes, (iii) studies conducted among general populations, and (iv) papers were written in English. The final date of the search was December 19, 2020. After applying these criteria, 33 studies for inclusion in this meta-analysis yielded a total of 66 effect sizes (see Figure 1 for a flow diagram).

\section{Coding of studies}

Studies were coded using the same set of coding guidelines. The following variables were coded: (i) mental health problems, (ii) correlation coefficients, (iii) sample size, (iv) participants' characteristics, (v) country of origin for the sample, and (vi) reliability of each measure in each study. In order to resolve discrepancies, several discussions between the authors were carried out until all issues had been addressed and consensus had been reached. The interrater agreement $(\kappa)$ was 94 .

\section{Meta-analytic procedure}

The analyses were performed using Comprehensive Meta-Analysis (CMA) software. The analysis transformed each effect size to Fisher's Zr then transformed back into correlations when reporting the results of the analyses for facilitating interpretation. The conclusions were based on the random-effects model. When groups are independent of each other, the random-effects model is more suitable for meta-analysis (Lipsey \& Wilson, 2001). Outliers on effect size variables were examined but no statistical outliers were found.

Figure 1 about here

\section{Results}

\section{Study sample characteristics}


Overall, 66 total effect sizes from 33 different studies were obtained and 70,407 individuals were included in this meta-analysis. Studies were conducted in Bangladesh, Brazil, China, Greece, Hong Kong, Iran, Israel, Italy, Japan, Malaysia, Pakistan, Peru, Saudi Arabia, Spain, Turkey, United Kingdom, United Arab Emirates, and United States. Studies utilizing a targeted sample group (e.g., healthcare professionals, patients) were excluded. All of the studies employed appropriate statistical methods.

\section{Publication bias}

The present study utilized Rosenthal's fail-safe N, Begg and Mazumdar rank correlation, and Duval and Tweedie's trim and fill analyses to identify publication bias (Begg \& Mazumdar, 1994; Duval \& Tweedie, 2000, Borenstein et al., 2011). Mullen et al. (2001) suggested that if $\mathrm{N}>(5 \mathrm{k}+10)$ ( $\mathrm{k}$ is the number of individual studies in the metaanalysis), the result of the meta-analysis is sufficiently robust for future studies. The analysis obtained $\mathrm{N}$ values 6734 for depression, 2166 for anxiety, 1942 for stress, 3874 for distress, 4057 for traumatic stress, and 125 for insomnia. For Begg and Mazumdar rank correlation, a $p>0.05$ value indicates no publication bias (Peng et al. 2018). The results indicated $p$-values of 0.36 for depression, 0.18 for anxiety, 0.44 for stress, 0.32 for distress, 0.43 for traumatic stress, and 0.30 for insomnia. Duval and Tweedie's trim and fill analysis is a type of analysis based on estimating the number of missing studies based on the symmetry assumption. It aims to obtain an unbiased sample by adding virtual studies (Duval \& Twedie, 2000). No missing studies were found as a result of this analysis. In sum, the results showed that there was no publication bias.

\section{Meta-analytic results}


Table 1 shows a number of independent correlation coefficients $(\mathrm{k})$, sample size $(\mathrm{N})$, mean weighted effect sizes (r), and homogeneity statistics for relationships with fear of COVID-19 fear and mental health problems. Results were interpreted utilizing Cohen, Manion, and Morrison's (2007) guidelines for correlations $(r<0.10$ very weak, $0.10 \leq r$ $<0.30$ weak, $0.30 \leq r<0.50$ moderate, $0.50 \leq r<0.80$ strong, and $r \geq 0.80$ very strong).

As shown in Table 1, fear of COVID-19 strongly positively related with anxiety $(r=.55)$, traumatic stress $(r=.54)$, and and distress $(r=.53)$. Moderately positive relationships were found between fear of COVID-19 and stress $(r=.47)$ and depression $(r=.38)$. Additionally, a small positive relationship was found between fear of COVID-19 and insomnia $(r=.27)$. The control of heterogeneity in the analysis was carried out utilizing Cochran's (1954) Q statistic and $\mathrm{I}^{2}$ statistic. The results of Q statistics found that all variables showed heterogeneity. $\mathrm{I}^{2}$ results showed the quantity of the heterogeneity $(25 \%$ low, $50 \%$ moderate, and $75 \%$ high). The analysis showed that all the studies had high heterogeneity.

Table 1 about here

\section{Discussion}

A recent and growing body of literature has given attention to the mental health effects associated with fear of COVID-19. Consequently, a meta-analysis was performed on studies examining the mental health problems related to the fear of COVID-19 utilizing the Fear of COVID-19 Scale (Ahorsu, Lin, Imani et al., 2020) - the most widely used psychometric scale specifically assessing fear of COVID-19. To the best of the authors' knowledge, the present study is the first to systematically review mental health 
problems related to the fear of COVID-19. The study included 33 different studies and 70,407 individuals, showed that the fear of COVID-19 had a significant association with mental health problems including depression, anxiety, stress, distress, traumatic stress, and insomnia.

First, results from 20 studies included in the meta-analysis showed a moderate mean weighted ES $r=0.38$ (95\% CI [0.34, 0.42] between fear of COVID-19 and depression. This finding is consistent with the view that different fears can be associated with depression (e.g., O'Connor et al., 2002). Second, results from 23 studies showed a strong mean weighted ES $r=0.55$ (95\% CI $[0.48,0.61]$ between fear of COVID-19 and anxiety. The fear of COVID-19 reflects the psychological nature of a phobia that falls under the classification of anxiety disorders (American Psychiatric Association, 2013). Therefore, it is not surprising to find such a strong relationship in the present study.

Seven studies were found examining the association between fear of COVID-19 and stress. Meta-analysis results from these studies showed a moderate mean weighted ES $r=0.47(95 \%$ CI $[0.31,0.59]$ between fear of COVID-19 and stress. For decades, the literature has emphasized that fear can cause stress (e.g., Gray, 1987; Nasar \& Jones, 1997; Shin \& Liberzon, 2010). Similarly, seven studies were found examining the association between fear of COVID-19 and distress. Results from these studies showed a strong mean weighted ES $r=0.53$ (95\% CI [0.45, 0.61] between fear of COVID-19 and distress. Distress is a negative general mood that includes depression, anxiety, and stress (Hodges \& Humphris, 2009). The authors of the present study consider the fear of COVID-19 to be one of the components of distress. The strong correlation obtained from the studies reviewed support this hypothesis. In addition to these findings, six studies 
were found investigating association between fear of COVID-19 and traumatic stress. Results from these studies showed a strong mean weighted ES $r=0.54$ (95\% CI [0.43, 0.63] between fear of COVID-19 and traumatic stress. Clinical diagnoses of fears that occur especially during crisis periods are typically in the form of traumatic stress (Gonzalez \& Martinez, 2014).

Finally, the results from three studies in the meta-analysis showed a weak average weight $\mathrm{ES} r=0.28$ (95\% CI [0.20, 0.37]) between fear of COVID-19 and insomnia. It is possible that the fear of COVID-19 among some individuals stimulates the brain and thereby causes insomnia (Lin et al., 2020). Therefore, it was expected that this effect would be greater. The correlations obtained from the studies found in the analysis were positive. Therefore, the average weighted ES obtained was positive. However, further studies are needed to verify this relationship. A recent review by Lakhan et al. (2020) reported that depression, anxiety, sleep disorders, and psychological distress were high among members of the general public during the COVID-19 pandemic. In a previous meta-analysis among individuals with COVID-19 (Deng et al., 2020), the frequency of depression was $45 \%$, anxiety frequency $47 \%$, and sleep disorders frequency $34 \%$. Additionally, another meta-analysis (de Pablo et al., 2020) on the effect of COVID-19 on healthcare workers' mental health was conducted. In the present meta-analysis, studies on healthcare workers were not included as the rate of virus transmission, witnessing deaths, and intense workloads meant that the fear of COVID-19 and negative psychological issues were likely to be higher. The meta-analysis here focused solely on mental health problems that may be related to the fear of COVID-19 among the general public.

\section{Limitations, implications, and future research}


Despite the present study presenting strong evidence on the association between fear of COVID-19 and mental health problems, it has some limitations. First, only papers published in English were reviewed, and there may be other non-English studies that we did not include in the meta-analysis. Second, the current meta-analysis included heterogeneous studies of mental health problems related to fear of COVID-19. Even though there were no signs of publication bias in the studies covered in the analysis, there may be studies not found as they were not listed in the databases selected. Third, incomplete data and selective notification of results of studies in the analysis may have led to an overestimation of mean ES. Fourth, the present meta-analysis was restricted to using only the FCV-19S to assess COVID-19 fear. Fifth, the present study only included the most frequently studied mental health problems related to the fear of COVID-19. Therefore, it is recommended that other researchers should focus on studies on different mental health problems that were not addressed in the present study related to the fear of COVID-19.

Despite these limitations, the results of the meta-analysis here offer important implications for community welfare. Considering that the fear of COVID-19 is related to depression, anxiety, stress, distress, traumatic stress, and insomnia, it would be useful for mental health professionals to educate the general public about coping with the fear and psychological effects of COVID-19. Although it cannot be claimed in this study that there is causality between the fear of COVID-19 and mental health difficulties, it is clear that healthcare providers should evaluate them together given the high associations found. 
In particular, policymakers should focus on preventive work concerning the fear of COVID-19. The association between fear and mental health problems in some countries included in the meta-analysis was strikingly greater than in others. When examining the measures taken by these countries against COVID-19, it was weaker than others. The fact that the present study showed that the fear of COVID-19 was related to many mental problems indicates that policies to reduce this fear should be developed and introduced.

\section{Conclusion}

For the first time, the present study demonstrated a strong association across nearly three dozen studies around the world between fear of COVID-19 and mental health problems among the general public during the COVID-19 pandemic. The strength of the association between fear of COVID-19 and mental health problems can be ordered as anxiety, traumatic stress, distress, stress, depression, and insomnia, respectively. Overall findings of the present study provide scholars and practitioners with a risk assessment of fear of COVID-19 in terms of mental health outcomes during the pandemic. Additionally, the meta-analysis here combined and summarized findings of primary studies on fear of COVID-19 and mental health difficulties into an easily understandable summary of key associations. 


\section{References}

(References with an asterisk denote the studies included in the meta-analysis)

*Abad, A., da Silva, J. A., de Paiva Teixeira, L. E. P., Antonelli-Ponti, M., Bastos, S., Mármora, C. H. C., ... \& da Silva, J. A. (2020). Evaluation of fear and peritraumatic distress during COVID-19 pandemic in Brazil. Advances in Infectious Diseases, 10(3), 184-194. https://doi.org/10.4236/aid.2020.103019

*Ahorsu, D. K., Lin, C. Y. \& Pakpour, A. H. (2020). The association between health status and insomnia, mental health, and preventive behaviors: the mediating role of fear of COVID-19. Gerontology and Geriatric Medicine, 6, 1-9. https://doi.org/10.1177/2333721420966081

*Ahorsu, D. K., Lin, C. Y., Imani, V., Saffari, M., Griffiths, M. D., \& Pakpour, A. H. (2020). The fear of COVID-19 scale: development and initial validation. International Journal of Mental Health and Addiction. Advance online publication. https://doi.org/10.1007/s11469-020-00270-8

*Alsalhe, T. A., Aljaloud, S. O., Chalghaf, N., Guelmami, N., Alhazza, D. W., Azaiez, F., \& Bragazzi, N. L. (2020). Moderation effect of physical activity on the relationship between fear of COVID-19 and general distress: A pilot case study in Arabic countries. Frontiers in Psychology, 11, 570085. https://doi.org/10.3389/fpsyg.2020.570085

*Alyami, M., Henning, M., Krägeloh, C. U., \& Alyami, H. (2020). Psychometric evaluation of the Arabic version of the Fear of COVID-19 Scale. International Journal of Mental Health and Addiction. Advance online publication. https://doi.org/10.1007/s11469-020-00316-X 
American Psychiatric Association. (2013). Diagnostic and statistical manual of mental disorders (DSM-5®). American Psychiatric Publishing. https://doi.org/10.1176/appi.books.9780890425596

*Bakioğlu, F., Korkmaz, O., \& Ercan, H. (2020). Fear of COVID-19 and positivity: mediating role of intolerance of uncertainty, depression, anxiety, and stress. International Journal of Mental Health and Addiction. Advance online publication. https://doi.org/10.1007/s11469-020-00331-y

Begg, C. B., \& Mazumdar, M. (1994). Operating characteristics of a rank correlation test for publication bias. Biometrics, 50(4), 1088-1101. https://doi.org/10.2307/2533446

BBC News (2020, December 22). Covid: How are European countries tackling the pandemic? https://www.bbc.com/news/explainers-53640249

*Bitan, D. T., Grossman-Giron, A., Bloch, Y., Mayer, Y., Shiffman, N., \& Mendlovic, S. (2020). Fear of COVID-19 scale: Psychometric characteristics, reliability and validity in the Israeli population. Psychiatry Research, 289, 113100. https://doi.org/10.1016/j.psychres.2020.113100

Broche-Pérez, Y., Fernández-Fleites, Z., Jiménez-Puig, E., Fernández-Castillo, E., \& Rodríguez-Martin, B. C. (2020). Gender and Fear of COVID-19 in a Cuban population sample. International Journal of Mental Health and Addiction, Advance online publication. https://doi.org/10.1007/s11469-020-00343-8 .

Borenstein, M., Hedges, L. V., Higgins, J. P., \& Rothstein, H. R. (2011). Introduction to meta-analysis. John Wiley \& Sons. 
Cassiani-Miranda, C. A., Tirado-Otálvaro, A. F., \& Campo-Arias, A. (2021). Adaptation and psychometric evaluation of the Fear of COVID-19 Scale in the general Colombian population. Death Studies. Advance online publication. https://doi.org/10.1080/07481187.2021.1874572

Cavalheiro, F. R. S., \& Sticca, M. G. (2020). Adaptation and Validation of the Brazilian Version of the Fear of COVID-19 Scale. International Journal of Mental Health and Addiction. Advance online publication. https://doi.org/10.1007/s11469-020$\underline{00415-9}$

Caycho-Rodríguez, T., Vilca, L. W., Cervigni, M., Gallegos, M., Martino, P., Portillo, N., ... \& Burgos Videla, C. (2020). Fear of COVID-19 scale: Validity, reliability and factorial invariance in Argentina's general population. Death Studies. Advance online publication. https://doi.org/10.1080/07481187.2020.1836071

Chi, X., Chen, S., Chen, Y., Chen, D., Yu, Q., Guo, T., ... \& Zou, L. (2021). Psychometric evaluation of the fear of COVID-19 scale among Chinese population. International Journal of Mental Health and Addiction. Advance online publication. https://doi.org/10.1007/s11469-020-00441-7

Cochran, W. G. (1954). The combination of estimates from different experiments. Biometrics, 10, 101-129. https://doi.org/10.2307/3001666

Coelho, C. M., Suttiwan, P., Arato, N., \& Zsido A. N. (2020) On the nature of fear and anxiety triggered by COVID-19. Frontiers in Psychology, 11, 5811314. https://doi.org/10.3389/fpsyg.2020.581314

Cohen, L., Manion, L., \& Morrison, K. (2007). Research methods in education. Routledge Falmer. https://doi.org/10.4324/9780203029053 
de Pablo, G. S., Serrano, J. V., Catalan, A., Arango, C., Moreno, C., Ferre, F., ... \& FusarPoli, P. (2020). Impact of coronavirus syndromes on physical and mental health of health care workers: Systematic review and meta-analysis. Journal of Affective Disorders, 275, 48-57. https://doi.org/10.1016/j.jad.2020.06.022

Deng, J., Zhou, F., Hou, W., Silver, Z., Wong, C. Y., Chang, O., Huang, E., \& Zuo, Q. K. (2020). The prevalence of depression, anxiety, and sleep disturbances in COVID-19 patients: A meta-analysis. Annals of the New York Academy of Sciences. Advance online publication. https://doi.org/10.1111/nyas.14506

Doshi, D., Karunakar, P., Sukhabogi, J. R., Prasanna, J. S., \& Mahajan, S. V. (2020). Assessing coronavirus fear in Indian population using the fear of COVID-19 scale. International Journal of Mental Health and Addiction. Advance online publication. https://doi.org/10.1007/s11469-020-00332-x

Duval, S., \& Tweedie, R. (2000). Trim and fill: a simple funnel-plot-based method of testing and adjusting for publication bias in meta-analysis. Biometrics, 56(2), 455-463. https://doi.org/10.1111/j.0006-341X.2000.00455.x

Elemo, A.S., Satici, S.A. \& Griffiths, M.D. (2020). The Fear of COVID-19 Scale: Psychometric properties of the Ethiopian Amharic version. International Journal of Mental Health and Addiction. Advance online publication. https://doi.org/10.1007/s11469-020-00448-0

García-Reyna, B., Castillo-García, G. D., Barbosa-Camacho, F. J., Cervantes-Cardona, G. A., Cervantes-Pérez, E., Torres-Mendoza, B. M., ... \& Cervantes-Guevara, G. (2020). Fear of COVID-19 Scale for Hospital Staff in Regional Hospitals in 
Mexico: a Brief Report. International Journal of Mental Health and Addiction, Advance online publication. https://doi.org/10.1007/s11469-020-00413-x

*Gasparro, R., Scandurra, C., Maldonato, N. M., Dolce, P., Bochicchio, V., Valletta, A., ... \& Marenzi, G. (2020). Perceived job insecurity and depressive symptoms among Italian dentists: The moderating role of fear of COVID-19. International Journal of Environmental Research and Public Health, 17(15), 5338. https://doi.org/10.3390/ijerph17155338

Gonzalez, P., \& Martinez, K. G. (2014). The role of stress and fear on the development of psychopathology. Psychiatric Clinics of North America, 37(4), 535-546. https://doi.org/10.1016/j.psc.2014.08.010.

Gray, J. A. (1987). The psychology of fear and stress (Vol. 5). CUP Archive.

Gullone, E. (2000). The development of normal fear: A century of research. Clinical Psychology Review, 20(4), 429-451. https://doi.org/10.1016/S02727358(99)00034-3

*Harper, C. A., Satchell, L. P., Fido, D., \& Latzman, R. D. (2020). Functional fear predicts public health compliance in the COVID-19 pandemic. International Journal of Mental Health and Addiction. Advance online publication. https://doi.org/10.1007/s11469-020-00281-5

*Hashemi, S. G. S., Hosseinnezhad, S., Dini, S., Griffiths, M. D., Lin, C. Y., \& Pakpour, A. H. (2020). The mediating effect of the cyberchondria and anxiety sensitivity in the association between problematic internet use, metacognition beliefs, and fear of COVID-19 among Iranian online population. Heliyon, 6(10), e05135. https://doi.org/10.1016/j.heliyon.2020.e05135 
Higgins, J. P., \& Thompson, S. G. (2002). Quantifying heterogeneity in a meta- analysis. Statistics in Medicine, 21(11), 1539-1558. https://doi.org/10.1002/sim.1186

Hodges, L. J., \& Humphris, G. M. (2009). Fear of recurrence and psychological distress in head and neck cancer patients and their carers. Psycho-Oncology: Journal of the Psychological, Social and Behavioral Dimensions of Cancer, 18(8), 841-848. https://doi.org/10.3389/fpsyg.2020.581314

*Huarcaya-Victoria, J., Villarreal-Zegarra, D., Podestà, A., \& Luna-Cuadros, M. A. (2020). Psychometric properties of a Spanish version of the Fear of COVID-19 Scale in general population of Lima, Peru. International Journal of Mental Health and Addiction. Advance online publication. https://doi.org/10.1007/s11469-020$\underline{00354-5}$

Iversen, M. M., Norekvål, T. M., Oterhals, K., Fadnes, L. T., Mæland, S., Pakpour, A. H., \& Breivik, K. (2021). Psychometric properties of the Norwegian version of the Fear of COVID-19 Scale. International Journal of Mental Health and Addiction. Advance online publication. https://doi.org/10.1007/s11469-020-00454-2

*Kira, I. A., Shuwiekh, H. A., Rice, K. G., Ashby, J. S., Elwakeel, S. A., Sous, M. S. F., ... \& Jamil, H. J. (2020). Measuring COVID-19 as traumatic stress: Initial psychometrics and validation. Journal of Loss and Trauma. Advance online publication. https://doi.org/10.1080/15325024.2020.1790160

Lakhan, R., Agrawal, A., \& Sharma, M. (2020). Prevalence of depression, anxiety, and stress during COVID-19 pandemic. Journal of Neurosciences in Rural Practice, 11(4), 519-525. https://doi.org/10.1055/s-0040-1716442 
Lee, S. A., \& Neimeyer, R. A. (2020). Pandemic Grief Scale: A screening tool for dysfunctional grief due to a COVID-19 loss. Death Studies. Advance online publication. https://doi.org/10.1080/07481187.2020.1853885

*Li, D. C. Y., \& Leung, L. (2020). Psychometric data on knowledge and fear of coronavirus disease 2019 and perceived stress among workers of filipino origin in Hong Kong. Data in Brief, 33, 106395. https://doi.org/10.1016/j.dib.2020.106395

Li, J. B., Yang, A., Dou, K., \& Cheung, R. Y. M. (2020). Self-control moderates the association between perceived severity of the coronavirus disease 2019 (COVID19) and mental health problems among the Chinese public. PsyArXiv Preprints. https://doi.org/10.31234/osf.io/2xadq

*Liang, S. W., Chen, R. N., Liu, L. L., Li, X., Chen, J. B., Tang, S. Y., \& Zhao, J. (2020). The psychological impact of the COVID-19 epidemic on Guangdong college students: The difference between seeking and not seeking psychological help. Frontiers in Psychology, 11, 2231. https://doi.org/10.3389/fpsyg.2020.02231

*Lin, C. Y., Broström, A., Griffiths, M. D., \& Pakpour, A. H. (2020). Investigating mediated effects of fear of COVID-19 and COVID-19 misunderstanding in the association between problematic social media use, psychological distress, and insomnia. Internet Interventions, 21, 100345.

https://doi.org/10.1016/j.invent.2020.100345

Lipsey, M. W., \& Wilson, D. (2001). Practical meta-analysis. Thousand Oaks, CA: Sage

*Mahmud, M. S., Talukder, M. U., \& Rahman, S. M. (2020). Does 'Fear of COVID19'trigger future career anxiety? An empirical investigation considering 
depression from COVID-19 as a mediator. International Journal of Social Psychiatry. Advance online publication.

https://doi.org/10.1177/0020764020935488

Magano, J., Vidal, D. G., Dinis, M. A. P., \& Leite, Â. (2021). Validation and Psychometric Properties of the Portuguese Version of the Coronavirus Anxiety Scale (CAS) and Fear of COVID-19 Scale (FCV-19S) and Associations with Travel, Tourism and Hospitality. International Journal of Environmental Research and Public Health, 18(2), 427. https://doi.org/10.3390/ijerph18020427

Mamun, M.A. \& Griffiths, M.D. (2020). First COVID-19 suicide case in Bangladesh due to fear of COVID-19 and xenophobia: Possible suicide prevention strategies. Asian Journal of Psychiatry, 51, 102073. https://doi.org/10.1016/j.ajp.2020.102073

*Martínez-Lorca, M., Martínez-Lorca, A., Criado-Álvarez, J. J., \& Armesilla, M. D. C. (2020). The fear of COVID-19 scale: validation in Spanish university students. Psychiatry Research, 293, 11350. https://doi.org/10.1016/j.psychres.2020.113350

*Masuyama, A., Shinkawa, H., \& Kubo, T. (2020). Validation and psychometric properties of the Japanese version of the fear of COVID-19 scale among adolescents. International Journal of Mental Health and Addiction. Advance online publication. https://doi.org/10.1007/s11469-020-00368-z

Miller, J. R. (2020, March 25). British teen dies after suicide attempt due to coronavirus fears. New York Post. https://nypost.com/2020/03/25/british-teen-diesaftersuicide-attempt-due-to-coronavirus-fears/ 
Ministry of the Interior. (2020, December 22). Koronavirüs ile mücadele kapsamında yeni kisitlama ve tedbirler genelgeleri. https://www.icisleri.gov.tr/koronavirus-ilemucadele-kapsaminda-sokaga-cikma-kisitlamalari---yeni-kisitlama-ve-tedbirlergenelgeleri

Mullen, B., Muellerleile, P., \& Bryant, B. (2001). Cumulative meta-analysis: A consideration of indicators of sufficiency and stability. Personality and Social Psychology Bulletin, 27(11), 1450-1462. https://doi.org/10.1177/01461672012711006

Nasar, J. L., \& Jones, K. M. (1997). Landscapes of fear and stress. Environment and Behavior, 29(3), 291-323. https://doi.org/10.1177/001391659702900301

*Nikopoulou, V. A., Holeva, V., Parlapani, E., Karamouzi, P., Voitsidis, P., Porfyri, G. N., ... \& Diakogiannis, I. (2020). Mental Health Screening for COVID-19: a Proposed Cutoff Score for the Greek Version of the Fear of COVID-19 Scale (FCV-19S). International Journal of Mental Health and Addiction. Advance online publication. https://doi.org/10.1007/s11469-020-00414-w

O’Connor, L. E., Berry, J. W., Weiss, J., \& Gilbert, P. (2002). Guilt, fear, submission, and empathy in depression. Journal of Affective Disorders, 71(1-3), 19-27. https://doi.org/10.1016/S0165-0327(01)00408-6

Pakpour, A.H., Griffiths, M.D., Chang, K.C., Chen, Y-P., Yi-Jie Kuo, Y-J. \& Lin, C.Y. (2020). Assessing the fear of COVID-19 among different populations: A response to Ransing et al. (2020). Brain, Behavior and Immunity, 89, 524-525. https://doi.org/10.1016/j.bbi.2020.06.006 
*Pang, N. T. P., Kamu, A., Hambali, N. L. B., Mun, H. C., Kassim, M. A., Mohamed, N. H., ... \& Jeffree, M. S. (2020). Malay version of the Fear of COVID-19 Scale: Validity and reliability. International Journal of Mental Health and Addiction. Advance online publication. https://doi.org/10.1007/s11469-020-00373-2

*Parlapani, E., Holeva, V., Voitsidis, P., Blekas, A., Gliatas, I., Porfyri, G. N., ... \& Diakogiannis, I. (2020). Psychological and behavioral responses to the COVID-19 pandemic in Greece. Frontiers in Psychiatry, 11, 821. https://doi.org/10.3389/fpsyt.2020.00821

Peng, P., Su, S., Fairley, C. K., Chu, M., Jiang, S., Zhuang, X., \& Zhang, L. (2018). A global estimate of the acceptability of pre-exposure prophylaxis for HIV among men who have sex with men: A systematic review and meta-analysis. AIDS and Behavior, 22(4), 1063-1074. https://doi.org/10.1007/s10461-017-1675-z

*Perz, C.A., Lang, B.A. \& Harrington, R. (2020). Validation of the Fear of COVID-19 Scale in a US College Sample. International Journal of Mental Health and Addiction. Advance online publication. https://doi.org/10.1007/s11469-020$\underline{00356-3}$

Ransing, R., Ramalho, R., Orsolini, L., Adiukwu, F., Gonzalez-Diaz, J. M., Larnaout, A., Pinto da Costa, M., Grandinetti, P., Bytyçi, D. G., Shalbafan, M., Patil, I., Nofal, M., Pereira-Sanchez, V., \& Kilic, O. (2020). Can COVID-19 related mental health issues be measured? [Editorial]. Brain, Behavior, and Immunity, 88, 32-34. https://doi.org/10.1016/j.bbi.2020.05.049

*Reizer, A., Koslowsky, M., \& Geffen, L. (2020). Living in fear: The relationship between fear of COVID-19, distress, health, and marital satisfaction among Israeli 
women. Health Care for Women International. Advance online publication. https://doi.org/10.1080/07399332.2020.1829626

Reznik, A., Gritsenko, V., Konstantinov, V., Khamenka, N., \& Isralowitz, R. (2020). COVID-19 fear in Eastern Europe: Validation of the Fear of COVID-19 Scale. International Journal of Mental Health and Addiction. Advance online publication. https://doi.org/10.1007/s11469-020-00283-3.

*Rodríguez-Hidalgo, A. J., Pantaleón, Y., Dios, I., \& Falla, D. (2020). Fear of COVID19, stress, and anxiety in university undergraduate students: A predictive model for depression. Frontiers in Psychology, 11, 591797. https://doi.org/10.3389/fpsyg.2020.591797

*Rossi, A., Panzeri, A., Pietrabissa, G., Manzoni, G. M., Castelnuovo, G., \& Mannarini, S. (2020). The anxiety-buffer hypothesis in the time of COVID-19: When selfesteem protects from the impact of loneliness and fear on anxiety and depression. Frontiers in Psychology, 11, 2177. https://doi.org/10.3389/fpsyg.2020.02177

*Sakib, N., Bhuiyan, A. I., Hossain, S., Al Mamun, F., Hosen, I., Abdullah, A. H., ... \& Mamun, M. A. (2020). Psychometric validation of the Bangla Fear of COVID-19 Scale: Confirmatory factor analysis and Rasch analysis. International Journal of Mental Health and Addiction. Advance online publication. https://doi.org/10.1007/s11469-020-00289-x

*Saravanan, C., Mahmoud, I., Elshami, W., \& Taha, M. H. (2020). Knowledge, anxiety, fear, and psychological distress about COVID-19 among university students in the 
United Arab Emirates. Frontiers in Psychiatry, 11, 582189. https://doi.org/10.3389/fpsyt.2020.582189

*Satici, B., Gocet-Tekin, E., Deniz, M. E., \& Satici, S. A. (2020). Adaptation of the Fear of COVID-19 Scale: Its association with psychological distress and life satisfaction in Turkey. International Journal of Mental Health and Addiction. Advance online publication. https://doi.org/10.1007/s11469-020-00294-0

*Schimmenti, A., Starcevic, V., Giardina, A., Khazaal, Y., \& Billieux, J. (2020). Multidimensional assessment of COVID-19-related fears (MAC-RF): A theorybased instrument for the assessment of clinically relevant fears during pandemics. Frontiers in Psychiatry, 11, 748. https://doi.org/10.3389/fpsyt.2020.00748

Shin, L., \& Liberzon, I. (2010). The neurocircuitry of fear, stress, and anxiety disorders. Neuropsychopharmacology, 35, 169-191. https://doi.org/10.1038/npp.2009.83

Smith, B. M., Twohy, A. J., \& Smith, G. S. (2020). Psychological inflexibility and intolerance of uncertainty moderate the relationship between social isolation and mental health outcomes during COVID-19. Journal of Contextual Behavioral Science, 18, 162-174. https://doi.org/10.1016/j.jcbs.2020.09.005

*Soraci, P., Ferrari, A., Abbiati, F. A., Del Fante, E., De Pace, R., Urso, A., \& Griffiths, M. D. (2020). Validation and psychometric evaluation of the Italian version of the Fear of COVID-19 Scale. International Journal of Mental Health and Addiction. Advance online publication. https://doi.org/10.1007/s11469-020-00277-1 
Srivastava, A., Bala, R., Srivastava, A. K., Mishra, A., Shamim, R., \& Sinha, P. (2020). Anxiety, obsession and fear from coronavirus in Indian population: a web-based study using COVID-19 specific scales. International Journal of Community Medicine and Public Health, 7(11), 4570-4577. https://dx.doi.org/10.18203/2394$\underline{6040.1 j \mathrm{cmph} 20204763}$

*Tsipropoulou, V., Nikopoulou, V. A., Holeva, V., Nasika, Z., Diakogiannis, I., Sakka, S., ... \& Parlapani, E. (2020). Psychometric properties of the greek version of FCV-19S. International Journal of Mental Health and Addiction. Advance online publication. https://doi.org/10.1007/s11469-020-00319-8

*Voitsidis, P., Nikopoulou, V. A., Holeva, V., Parlapani, E., Sereslis, K., Tsipropoulou, V., ... \& Diakogiannis, I. (2020). The mediating role of fear of COVID- 19 in the relationship between intolerance of uncertainty and depression. Psychology and Psychotherapy: Theory, Research and Practice. Advance online publication. https://doi.org/10.1111/papt.12315

*Wakashima, K., Asai, K., Kobayashi, D., Koiwa, K., Kamoshida, S., \& Sakuraba, M. (2020). The Japanese version of the Fear of COVID-19 scale: Reliability, validity, and relation to coping behavior. PloS One, 15(11), e0241958.

\section{https://doi.org/10.1371/journal.pone.0241958}

Winter, T., Riordan, B. C., Pakpour, A. H., Griffiths, M. D., Mason, A., Poulgrain, J. W., \& Scarf, D. (2020). Evaluation of the English version of the Fear of COVID-19 Scale and its relationship with behavior change and political beliefs. International Journal of Mental Health and Addiction. Advance online publication.

https://doi.org/10.1007/s11469-020-00342-9 
World Health Organization (2020a, February 7). Coronavirus disease (COVID-19).

https://www.who.int/emergencies/diseases/novel-coronavirus-2019

World Health Organization (2020b, February 7). COVID-19 weekly epidemiological update. https://www.who.int/publications/m/item/weekly-epidemiological-update--2-february-2021

Xiang, Y. T., Yang, Y., Li, W., Zhang, L., Zhang, Q., Cheung, T., \& Ng, C. H. (2020). Timely mental health care for the 2019 novel coronavirus outbreak is urgently needed. The Lancet Psychiatry, 7(3), 228-229. https://doi.org/10.1016/S2215$\underline{0366(20) 30046-8}$ 
Table 1

Results of the Meta-Analyses for Covid-19 Fear and Mental Health Outcomes

\begin{tabular}{lllllll}
\hline Mental Health Outcomes & $k$ & $N$ & $R$ & $95 \% C I$ & $Q$ & $I^{2}$ \\
\hline Depression & 20 & 23835 & 0.38 & {$[0.34,0.42]$} & 271.37 & $92.9 \%$ \\
Anxiety & 23 & 19578 & 0.55 & {$[0.48,0.61]$} & 894.52 & $97.5 \%$ \\
Stress & 7 & 4340 & 0.47 & {$[0.31 .0 .59]$} & 199.30 & $96.9 \%$ \\
Distress & 7 & 11785 & 0.53 & {$[0.45,0.61]$} & 12.61 & $95.1 \%$ \\
Traumatic Stress & 6 & 8752 & 0.54 & {$[0.43,0.63]$} & 184.39 & $97.2 \%$ \\
Insomnia & 3 & 2114 & 0.27 & {$[0.23,0.31]$} & 8.55 & $76.6 \%$ \\
\hline
\end{tabular}

$\mathrm{k}=$ number of study outcome, $N=$ total sample size, $r=$ effect sizes, $\mathrm{CI}=$ confidence interval; Q = Cochran's homogeneity statistic; $\mathrm{I}^{2}=$ Higgins and Thompson's (2002) measure of heterogeneity 


\section{Figure 1}

\section{PRISMA flow Diagram of Study Selection}

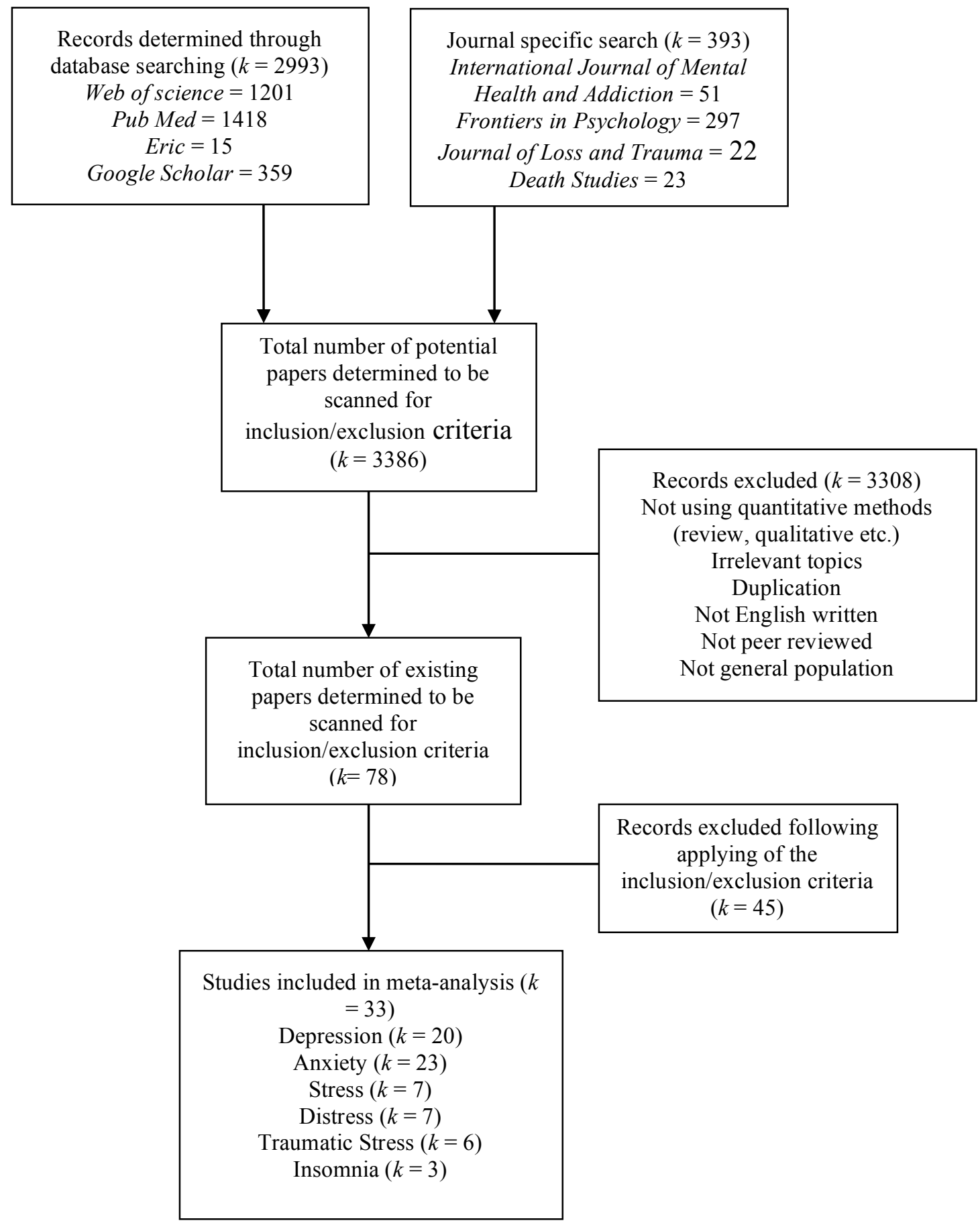

